\title{
Letter to the Editor. Animal Model for IRDS/ BPD-Problem of Species' Differences in Lung Maturation at Birth
}

\author{
LEE FRANK \\ Pulmonary Division, University of Miami, Miami, Florida, USA
}

In the September issue of Pediatric Research (Vol. 16: 798805 ), Dr. Allen T. Merritt reports an excellent study on the effect of hyperoxia in newborn guinea pigs and the effect of high $\mathrm{O}_{2}$ exposure on lung lavage cell populations and elastase content (1).

There is one question I have which I think needs some explication if one is to accept the key premise of the paper i.e., that elastase activity is an important marker for ongoing inflammatory cell injury in the $\mathrm{O}_{2}$-toxic lung. This relates to Figure 4 which shows that the total elastase activity in $\mathrm{FiO}_{2} .21$ at all times exceeds the total elastase activity recoverable in lavage fluid from the $\mathrm{FiO}_{2}$ $>.9$ exposed guinea pigs. This was apparently not the case when the total elastase activity in the human infants was assayed. Is there any hypothesis that may help to explain these discrepancies?

The other thing I believe should be pointed out relates to the animal model used and whether it is appropriate to extrapolate experimental findings from the newborn guinea pig to the newborn and especially the premature human infant. Unlike other common experimental animals used for newborn $\mathrm{O}_{2}$ toxicity studies (mouse, rat, rabbit), the guinea pig newborn is actually quite a mature animal at birth, especially in terms of lung development. For example, in the newborn guinea pig, alveolar wall thickness (tissue barrier for respiratory exchange) is similar to the adult value and the differentiation, alveolarization and lung remodeling that occurs in the other species mentioned above, and in man, postnatally, has already taken place for the most part prenatally in the guinea pig $(2,3)$. Northway's (4) study on $\mathrm{O}_{2}$ toxicity in the guinea pig (cited by the author) also shows very well the mature "lace-like" architecture of the newborn guinea pig lung. In some biochemical responses to $\mathrm{O}_{2}$ exposure, the lung of the newborn guinea pig again resembles that of an adult animal more so than that of a "typical" newborn (5). The same is true of histochemical analysis (lung glycogen, alkaline phosphatase activity, etc.) (3).

Because of the relative maturity of the newborn guinea pig lung it may be more appropriate to consider the changes found by the author as more representative of adult respiratory distress syndrome rather than as a model of severe $\mathrm{O}_{2}$ toxicity in premature infants progressing to bronchopulmonary dysplasia.

My comments are meant to be constructive ones and do not detract from the thoroughness of these studies and the new information made available from the author's careful work. The finding of increased elastase activity in sick newborns on prolonged $\mathrm{O}_{2}$ therapy may indeed turn out to be a useful marker for the development of progressive lung injury during and even after hyperoxic therapy.

\section{REFERENCES AND NOTES}

1. Merritt, A. T.: Oxygen exposure in the newborn guinea pig. Lung lavage cell populations, chemotactic and elastase responses: a possible relationship to neonatal bronchopulmonary dysplasia. Pediatr. Res., 16: 798 (1982).

2. Lechner, A. J. and Canchero, N.: Advanced pulmonary development in newborn guinea pigs (Cavia porcellus). Amer. J. Anat., 163: 235 (1982).

3. Sorokin, S., Padykula, H. A., and Herman, E.: Comparative histochemical patterns in developing mammalian lungs. Develop. Biol., $1: 125$ (1959).

4. Northway, W. H., Jr., Rosan, R. C., Shahinian, L., Jr., Castellino, R. A., Gyepes M. T., and Durbridge, T.: Radiologic and histologic investigation of pulmonary oxygen toxicity in newborn guinea pigs. Invest. Radiol., 4: 148 (1969).

5. Frank, L., Bucher, J. R., and Roberts, R. J.: Oxygen toxicity in neonatal and adult animals of various species. J. Appl. Physiol., 45: 577 (1979).

Printed in U.S.A. 